\title{
Freguesias fluminenses ao final do Setecentos ${ }^{1}$
}

\section{Fania Fridman ${ }^{2}$}

\section{Resumo}

O trabalho apresenta resultados de uma pesquisa em andamento que trata da formação das freguesias no Rio de Janeiro. Estas aglomerações, que contavam com atividades agrícolas e citadinas, constituíamse em núcleos de povoamento e mercados locais. Até o final do século XVIII, dezenas de freguesias haviam sido estabelecidas, partindo do litoral em direção ao sertão. Tais polos cristãos, fundados pela Igreja em parceria com a "nobreza da terra", apontam para a existência de uma rede urbana e de estratégias territoriais no projeto ultramarino português.

\section{Palavras chaves}

Freguesias, Rio de Janeiro, rede urbana, projeto colonial português.

1 Uma versão preliminar foi publicada nos Anais do X Seminário de História da Cidade e do Urbanismo. Anpur/UFPe, 2008. Agradeço a Valter Luiz de Macedo pela elaboração dos dois mapas inéditos.

2 Professora do Instituto de Pesquisa e Planejamento Urbano e Regional da Universidade Federal do Rio de Janeiro e pesquisadora do CNPq. E-mail: fania@ippur.ufrj.br 


\title{
Rio de Janeiro's parishes at the end of the 18th
}

\begin{abstract}
This article presents results of a research in progress that treats of the formation of the parishes in Rio de Janeiro. These villages, involved in agricultural and urban activities, were composed by nucleuses of population and local markets. By the end of the 18th century, dozens of parishes had been established from the coast line to the remote interior. These Christian poles, founded by the Church in association with the landlords, indicate the existence of a urban network and territorial strategies in the colonial project of Portugal.
\end{abstract}

Keywords

Parishes, Rio de Janeiro, urban network, colonial project of Portugal. 


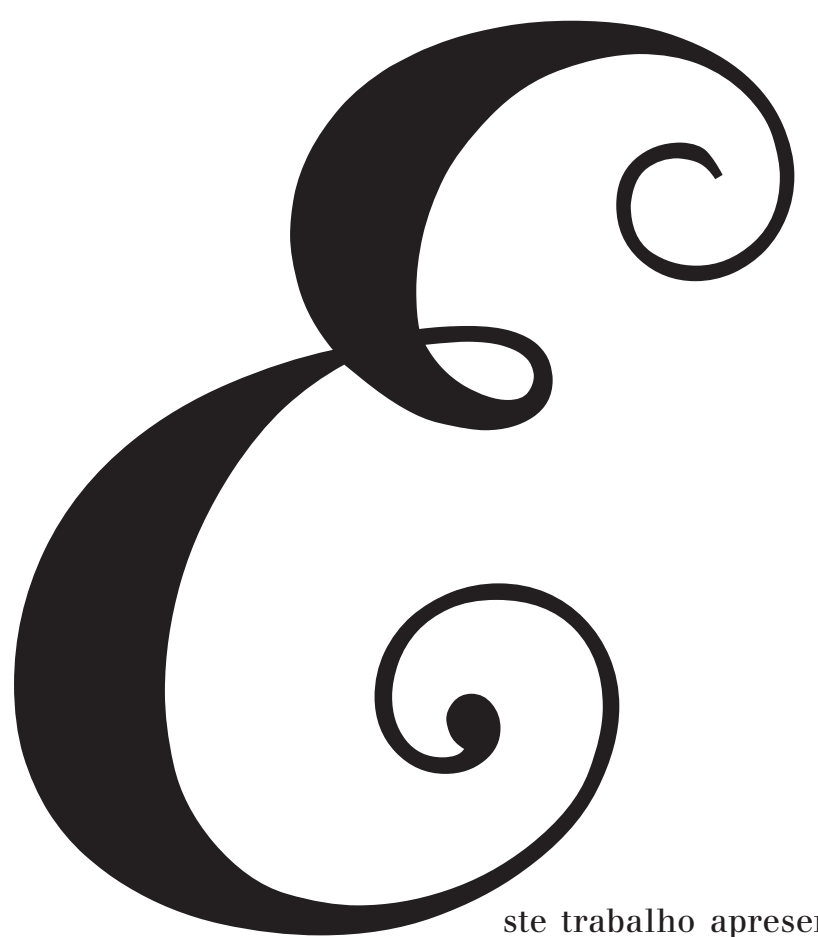

Introdução investigação ${ }^{3}$ em andamento dedicada à produção do espaço fluminense e à natureza da ingerência do Estado e de seus agentes em uma perspectiva histórica. Cabe inicialmente uma nota explicativa do porquê da escolha do tema e qual a sua pertinência: para se entender um país é preciso acompanhar a formação de seu território desde as unidades mais modestas - arraiais, aldeias, povoados e freguesias - até as vastas extensões que acabam por delimitar suas fronteiras. Contribuições recentes apontam que os programas de ação governamental vêm de longa data. Contudo, há necessidade do desenvolvimento de estudos que os registrem de maneira sistemática, de modo a se poder contar com um repertório dos diversos projetos e atores e das lutas que foram travadas para sua concretização.

De acordo com dois importantes historiadores brasileiros, Caio Prado Jr. e Fernando Novais, a colonização é um ponto de partida fundamental. E se recorrermos a Bosi quando diz "colo é a matriz de colônia enquanto espaço que se está ocupando, terra ou povo que se quer trabalhar ou sujeitar [...] tomar conta de, no sentido básico de colo, importa

3 Espaço e plano: capítulos da urbanização fluminense desenvolvida no âmbito do Grupo de Estudos do Território e de História Urbana vinculado ao Instituto de Pesquisa e Planejamento Urbano e Regional/UFRJ, com apoio do CNPq e da Faperj.

93

revista ieb $n_{49} 2009$ mar/set p. $x$-xx 
não só em cuidar, mas também em mandar" indagaremos acerca dos agentes da dominação. Aquele que desempenhou papel fundamental neste processo de sujeição foi a Igreja católica que, desde a Idade Média, através de suas circunscrições ou polos de "cristianização" - paróquias, dioceses e províncias metropolitanas -, possuía a vocação de dominar as áreas e definir o quadro de vida cotidiana, isto é, "colonizar e evangelizar se colocam em pé de igualdade [...]"5 . A instituição eclesiástica vivia sob o padroado, um regime definido como a soma de privilégios e vantagens concedidas pelo papa ao grão-mestre da Ordem de Cristo em favor da dilatação da fé e da manutenção do culto. Este era o método pelo qual o governo português cumpria sua função de "proteção" sobre a Igreja, cabendo ao monarca promover a criação de dioceses, apresentar os nomes dos escolhidos para ocupar as prelazias e capelas, a obrigação de construir e conservar os edifícios de culto e remunerar o clero, promovendo assim a expansão da fé cristã. Em troca, recebia o direito de cobrar e administrar os dízimos pagos pelos fiéis. O rei exercia o governo civil e religioso no ultramar através de seus representantes, entre eles os clérigos que se tornavam funcionários ao receberem a côngrua paga pela Fazenda Real ${ }^{6}$.

O estudioso que se dedica ao período confronta-se com a falta de investigações concernentes ao papel que as freguesias exerceram na produção da rede urbana e à multiplicação de seu número e de seu patrimônio fundiário. Do ponto de vista metodológico, a pesquisa em curso contempla uma geo-história e um conjunto de elementos interdependentes na longa duração, tal como proposto pela Escola dos Annales, debruçando-se sobre o processo de produção do (atual estado) Rio de Janeiro originado de três capitanias - a de São Thomé, a segunda porção de São Vicente e a pequena capitania real do Rio de Janeiro encravada na delimitação de São Vicente. Serão tratadas, neste texto, a gênese e/ou consolidação das capelas ao final do século XVIII na capitania do Rio de Janeiro que já se configurava como centro articulador de grandes regiões do Império português.

4. BOSI, Alfredo. Dialética da colonização. São Paulo: Companhia das Letras, 1992. p. 11.

5 AZZI, Riolando. A instituição eclesiástica durante a primeira época colonial. In: HOORNAERT, Eduardo (Coord.). História da Igreja no Brasil. Rio de Janeiro: Ed. Paulinas; Petrópolis: Ed. Vozes, 1992. t. II/1, p. 211.

6 “Este será o regime de provimento dos cargos eclesiásticos no período colonial: o rei apresenta ao papa os bispos na qualidade de chefe de Estado; e no de grãomestre da Ordem de Cristo apresenta aos bispos os beneficiários para os cabidos, paróquias e capitanias". LACOMBE, A. J. Ordens religiosas, irmandades e confrarias. In.: RIHGB (288), jul-set 1970. p. 55. À Ordem de Cristo cabia a jurisdição espiritual sobre as terras conquistadas que não pertencessem a nenhuma diocese. 
A historiografia, sobretudo com as contribuições de João Fragoso e Manolo Florentino, vem se dedicando ao papel desempenhado pelas atividades econômicas e às diversas camadas sociais presentes na cidade após a descoberta do ouro nas Minas e a posterior transferência da sede política do Vice-Reino de Salvador para o Rio de Janeiro em 1763, demonstrando como as redes de negócios articularam-se às políticas "modernizadoras" de Pombal no que tange à diversificação agrícola e às reformas institucionais. Pretende-se aqui discutir como a elevação de povoados a freguesias fez parte do projeto pombalino ao intensificar a circulação e o domínio territorial e político.

\section{As freguesias}

Para a gestão da metrópole, as donatarias dividiam-se em comarcas abarcando os termos das vilas e cidades e estes se fracionavam em freguesias (ou paróquias ou capelas) "o que evidencia carência de sólida distinção conceitual entre poderes civil e eclesiástico, levando aquele a servir-se da freguesia, circunscrição deste, confirmando a regra, frequente, de a organização religiosa preceder à civil"7. A freguesia, designação portuguesa de paróquia, é um território submetido à jurisdição espiritual de um cura que também exerce a administração civil. A palavra paróquia vem do grego parochos (aquele que fornece as coisas necessárias) ou paroikia (vizinhança; para, perto e oikos, casa). Trata-se de uma circunscrição eclesial em que se divide a diocese, palavra igualmente de origem grega e utilizada no Império romano, que tem o sentido de governo. Sua multiplicação vertiginosa estabilizou-se nos séculos XII e XIII, quando se submeteu aos cuidados espirituais de um bispo pago pelo rei com rendas do dízimo. "Os bispos eram considerados nobres vinculados à coroa real, e portanto sua atuação religiosa estava limitada com frequência aos interesses políticos". Cada bispado supunha a existência de uma cidade - o do Rio de Janeiro foi concebido em 1676 e ia até o sul do Brasil ${ }^{9}$. Separada por razões especiais de um bispado, a prelazia ou vigararia é uma área de transição para a categoria de diocese na qual

7 Idem. A igreja no Brasil colonial. In: História geral da civilização brasileira, v. 2. Rio de Janeiro: Bertrand Brasil, 7. ed., 1993. p. $5^{2}$.

8 AZZI, Riolando. op. cit., p. 172.

9 A primeira diocese foi a da Bahia (1551), seguida por Pernambuco e Maranhão (1676). O bispado do Pará (1719) submetia a região amazônica, o de Mariana (1745), o centro-oeste. No mesmo ano, foi organizado o de São Paulo e nenhum outro foi criado até a Independência, daí apresentarem extensão tão ampla. Até hoje as arquidioceses ou províncias situam-se em cidades de particular importância políti- 
um sacerdote representa o poder legal com autonomia administrativa. A prelazia do Rio de Janeiro foi erigida já em 1576 e, no momento da criação do bispado, formaram-se algumas vigararias, conforme observaremos adiante.

Ainda que a estrutura eclesiástica implantada tenha sido altamente centralizadora ${ }^{10}$, Hoornaert diz ter sido o Brasil colonial um "conglomerado de cristandades": em cada localidade mandava uma família "dona" da religião e onde o padre estava mais ligado ao clã que ao bispo. A vida política também possuía caráter local: se o início de uma pequena povoação era sempre um cruzeiro ou capela, cuja acomodação dependia do patrimônio do santo, isto é, das terras doadas pelos grandes proprietários fundiários, tal fato pode ser interpretado como um sistema patriarcal do domínio político ${ }^{11}$ e uma mistura entre a coisa pública e o negócio privado na ordem espacial.

Coexistiam dois tipos de capelas: as colativas e as curadas. Nas primeiras, mais raras, os párocos, selecionados por concurso, exerciam seu ofício mantidos pela Fazenda Real. As curadas eram dependentes das "benesses de pé do altar". Quando as dispersas comunidades se institucionalizavam pela elevação de sua ermida a paróquia, confirmada por um alvará que também determinava os seus limites, o governo começava a exercer o padroado sobre elas, mantendo-as com as rendas provenientes dos dízimos da Ordem de Cristo. Afora o Estado estabelecer tais instâncias - as menores do poder instituído - em assentamentos com a atenção da Igreja, a população também procurou oficializar arraiais em regiões inóspitas ou de ocupação mais antiga ou em expansão para garantir e ampliar seu prestígio ${ }^{12}$. Parece também evidente que a necessidade de ermidas onde os fiéis pudessem satisfazer suas obrigações religiosas foi aumentando à medida que a população crescia, além das construções pias representarem locais de encontro onde ocorria uma boa parte da vida social.

O Concílio de Trento e as Constituições Primeiras do Arcebispado da Bahia (1707) - um conjunto de normas para as terras portuguesas no

ca, econômica, histórica ou religiosa, são autônomas e só devem obediência diretamente ao papa.

10 Quanto aos curas (de curati, incumbidos da cura), estes não podiam ser membros de ordem regular, hereges, judeus, negros, mulatos nem portadores de defeito físico ou de impedimento canônico.

11 OMEGNA, Nelson. A cidade colonial. Brasília: Ebrasa; Instituto Nacional do Livro, 2. ed., 1971 .

12 A estabilidade social de uma localidade também era facilitada pelo convento, que dava prestígio e facilitava a promoção de um povoado a vila ou de vila a cidade. MARX, Murillo de Azevedo. Cidade no Brasil. Terra de quem?. São Paulo: Nobel; Edusp, 1991. 
Brasil - regravam a vida social, pois a instituição cristã era, como dito acima, o principal balizador da mentalidade e da moral. Estava previsto o dote anual de cada igreja paroquial (maior para aquelas erguidas em vilas), assim como a esmola real para a sua edificação, manutenção ou reforma. A licença para a sua construção estaria condicionada à sua localização - lugares decentes, em sítio alto, livre de umidade e "desviado de lugares imundos e sórdidos e de casas particulares, e de outras paredes, em distância que possam andar as procissões ao redor delas [...] em lugar $^{13}$ povoado onde estiver o maior número de fregueses"14. Aos bispos caberia a provisão, a colação e a instituição dos santuários, a serem confirmados posteriormente pelo rei ${ }^{15}$.

Como tais aglomerações, isto é, as freguesias, contendo pelo menos dez casas ou famílias, revelavam um mercado local onde eram exercidas atividades rurais e urbanas, não seria exagerado supor que, acompanhando o ritmo da colonização, concretizassem uma política urbanizadora, ou seja, expressassem uma ordem urbana de base patrimonial e eclesiástica. Neste sentido o estabelecimento de uma igreja matriz

é índice seguro da existência de núcleos ou centros de povoamento com suficiente densidade demográfica para justificar a sua instalação [...]. Assim, pelo estudo das datas das sesmarias e das resoluções régias que confirmaram a criação das freguesias é possível situar os pontos de povoamento e conjecturalmente retraçar os caminhos que os ligavam à cidade ${ }^{16}$.

A primeira freguesia, a de São Sebastião, foi fundada em 1569 com área coincidente com o termo da capitania real. Entre 1634 e 1697, foram criadas 16 paróquias - Nossa Senhora da Candelária; Nossa Senhora da Conceição, orago da vila de Angra dos Reis; Nossa Senhora d’Apresentação, orago de Irajá; São João Batista, orago de Meriti; São Gonçalo, orago de São Gonçalo; Santo Antônio de Sá, orago da vila em Macacu; São Nicolau, orago de Suruí; Nossa Senhora do Loreto, orago

13 De acordo com os dicionários Bluteau (1712), Moraes Silva (1813) e Vieira (1873), lugar é povoação pequena, menor que vila e maior que aldeia. BLUTEAU, Raphael. Vocabulario portuguez e latino. Coimbra: Real Collegio das Artes da Companhia de Jesus, 1712-9. MORAES SILVA, Antonio de. Diccionario da lingua portugueza. Lisboa: Typ. Lacerdina, 2. ed., 1813. VIEIRA, fr. Domingos. Grande diccionario portuguez ou Thesouro da lingua portugueza. Porto: Editores Ernesto Chardron e Bartholomeu H. de Moraes, 1873.

14. Título XVI, $\$ 687$, p. $25^{2}$.

15 Título XXII, $\mathbb{S} 5^{18}$.

16 LACOMBE, A. J. op.cit., p. 188. 
de Jacarepaguá; Santo Antônio, orago de Jacutinga; Nossa Senhora dos Remédios, orago da vila de Paraty; Nossa Senhora do Desterro, orago do Campo Grande; São João Batista, orago de Itaboraí; Nossa Senhora do Pilar, orago do Iguaçu; Nossa Senhora da Piedade, orago de Inhomirim; Nossa Senhora da Piedade, orago da vila de Magé e São João Batista, orago de Icaraí. A pujança econômica de Nossa Senhora do Desterro (Campo Grande) ocasionou sua elevação a prelazia em 1673 e, vinte anos após o Rio de Janeiro ter se tornado sede de bispado (1676), foram erigidas em vigararias Nossa Senhora da Piedade (Magé), Nossa Senhora do Pilar (Iguaçu), Nossa Senhora da Piedade (Inhomirim), São João Batista (Icaraí) e São João Batista (Itaboraí) ${ }^{17}$.

A corrida do ouro, descoberto ao final do século XVII, deu origem à abertura de caminhos e à conquista das terras fluminenses através da doação de sesmarias e da fundação de roças, estalagens, casas de comércio, postos de fiscalização, arraiais e de freguesias no interior da capitania - até então ocupado descontinuamente pelos brancos - através do apoderamento das terras dos nativos, exterminados física ou culturalmente pela submissão às aldeias de repartição. Organizadas desde 1575, serviam para submeter os silvícolas e utilizá-los no domínio do território, na segurança dos caminhos e na produção econômica ${ }^{18}$. Notase, no mapa 1, a importância de sua localização - no litoral, servindo de guarda, ou nas margens dos rios, facilitando a comunicação. A partir da reforma pombalina, as de São Pedro do Cabo Frio, São Francisco Xavier de Itaguaí, Nossa Senhora da Guia de Mangaratiba, São Lourenço, São Barnabé, Nossa Senhora das Neves e Santa Rita, Sacra Família de Ipuca, Santo Antônio de Guarulhos, Nossa Senhora da Glória de Valença, São

17 "É bem sabido que à Freguesia de Nossa Senhora da Candelária desta Cidade de São Sebastião foi sujeito, a princípio, todo o território da banda d'além pelo que pertencia ao pasto espiritual; e que pela extensão e longitude fazendo-se impraticável a mesma administração aos Fregueses que naqueles continentes habitavam, e à proporção da cultura que iam tendo as terras, se multiplicavam: foi de necessidade que se erigissem algumas Capelas e nelas houvessem Capelães Curados pelos Revmos. Administradores da Jurisdição Eclesiástica desta Capitania. [...] Pelos anos posteriores representando-se à S. Mage a grande necessidade que havia de se erigirem e criarem neste Bispado algumas Vigararias, assim por parte do Povo e moradores desta Capitania como pela informação que sobre a mesma matéria deu o Revmo. Administrador ou Governador do Bispado (por ausente em Lisboa o Ilmo. Sr. Bispo D. José de Barros de Alarcão) e de que foi encarregado por S. Mage, houve o mesmo Senhor por bem mandar erigir em Vigararia as mesmas Capelas ditas, ordenando também que lhes fossem assinados termos e limites pelo seu Alvará de 18 de janeiro de 1696 ". Arquivo da Cúria Metropolitana do Rio de Janeiro - ACMRJ; Livro de visitas pastorais, fls. 183, 184 .

18 FRIDMAN, Fania. Três vilas da Província Fluminense. Estudos de História da Unesp (2), 2001. 
Antônio do Rio Bonito, São Fidélis de Sigmaringa, São José de Leonissa, Santo Antônio de Pádua e São Luiz Beltrão, que já se constituíam em freguesias, tomaram denominações de vilas do reino e suas terras esbulhadas pelos colonos ${ }^{19}$.

Nos dois primeiros quartéis do Setecentos constituíram-se mais 10 freguesias - Nossa Senhora da Piedade, orago do Iguaçu; Nossa Senhora da Guia, orago de Pacobaíba; Nossa Senhora d'Ajuda, orago da Ilha do Governador; Nossa Senhora do Desterro, orago de Itambi; Santíssima Trindade, orago de Santíssima Trindade; Nossa Senhora da Conceição, orago do Alferes; São João Marcos, orago de João Marcos; Nossa Senhora da Conceição, orago de Campo Alegre; São Tiago, orago de Inhaúma e Sacra Família, orago do Caminho do Tinguá ${ }^{20}$. Na segunda metade do século mais povoações foram elevadas a paróquia - São Salvador do Mundo, orago de Guaratiba; Nossa Senhora d'Ajuda, orago de Guapimirim; Nossa Senhora do Amparo, orago de Maricá; Nossa Senhora de Nazaré, orago de Saquarema; Santana de Macacu; Nossa Senhora da Conceição, São Pedro e São Paulo, orago da Paraíba, caminho de Minas Gerais; São Lourenço, orago da aldeia dos índios; Nossa Senhora da Conceição, orago de Marapicu; São Francisco Xavier, orago da aldeia de Itaguaí; São Barnabé, orago da aldeia dos índios; Nossa Senhora da Conceição, orago de

19 Na carta régia de 18 de janeiro de 1751 , endereçada ao governador da capitania, d. José I determinava a domesticação do "gentio bravo" em todos os "sertões que correm para a parte do norte da capitania”, além da criação, na cidade do Rio de Janeiro, de uma Junta de Missões presidida pelo governador e composta pelo bispo, ouvidor, juiz de fora e pelos prelados tanto provinciais como das religiões com conventos e colégios. Logo após a expulsão dos loyolistas de todos os domínios portugueses em 1759, o governador enviou um ofício ao secretário de Estado informando a ereção de freguesias e vilas nos locais onde existiram aldeias da Companhia de Jesus para facilitar a cobrança dos dízimos e comentando sobre a má educação dada pelos padres aos índios que os tornou "incapazes, indolentes e insolentes". Em 1798 , quando um decreto extinguiu as reduções, seus bens foram vendidos pelo Tesouro e os silvícolas, agora considerados órfãos, passaram a trabalhar em serviços públicos ou distribuídos aos colonos, ou ainda vendidos e marcados a ferro como escravos (AN Fundo Secretaria de Estado do Brasil; códice 80, vol. o9, folhas 37v e 38; Projeto Resgate AHU_ACL_CU_017, Cx. 51, D. 5.076; AHU_ACL_CU_017, Cx. 61, D. 5.825; AHU_ACL_CU_o17, Cx. 64, D. 6.097; AHU_ACL_CU_017, Cx. 110, D. 9.139).

20 Em 17 de julho de 1719, o bispo do Rio de Janeiro escreveu uma carta ao rei em resposta à provisão em que foi determinado o envio da lista dos moradores do Bispado incluindo o número de escravos, mulheres e crianças. Descrevia a dificuldade em se cumprir tal ordem devido à pouca comunicação entre uma localidade e outra. A fiscalização sobre o território e os moradores pode ser constatada pelo ofício de 13 de junho de $175^{6}$ que o secretário de Estado da Marinha e Ultramar enviou ao bispo do Rio de Janeiro ordenando a elaboração de relações nominais de todas as vilas e povoados, indicando as distâncias e os rios navegáveis, bem como o número de habitantes e de capelas (Projeto Resgate AHU_ACL_CU_o17, Cx. 10, D. 1.147; AHU_ACL_CU_017, Cx. 50, D. 5.049 e D. 5.050). 
Iguaba; Sacra Família, orago da aldeia de Ipuca; Nossa Senhora da Guia, orago da aldeia de Mangaratiba; Nossa Senhora da Conceição, orago do Rio Bonito, Santíssimo Sacramento, orago de Cantagalo e São Sebastião, orago de Araruama ${ }^{21}$. O mapa 2 apresenta as delimitações, conjecturais, a partir das informações obtidas nas visitas pastorais do monsenhor Pizarro $^{22}$. Percebe-se a disparidade de extensões, definidas de acordo com a conquista, a colonização da área partindo da cidade do Rio de Janeiro e da importância econômica e política/ideológica exercida pelos poderosos das localidades.

O Rio de Janeiro era a entrada e saída das Gerais, servindo de porto escoador do ouro e de entreposto comercial. Como a região da mais importante cidade portuguesa do além-mar necessitava de segurança, ampliaram-se as obras de defesa restaurando ou construindo fortificações e organizaram-se tropas ${ }^{23}$ e postos de fiscalização (registros) para coibir o contrabando. Medida fundamental vinculou-se aos povoados, capelas e vilas. O secretário de Estado da Marinha e Ultramar, Francisco Xavier de Mendonça Furtado, ordenou o recolhimento de "todos os vadios e fascínoras que perturbavam a quietude da capitania" que viviam nos sertões da capitania, assentando-os obrigatoriamente em lugares com mais de cinquenta fogos para que fossem mantidos sob a vigilância das autoridades. Nos ofícios de fevereiro e abril de 1767, o vice-rei do Brasil, dirigindo-se ao secretário de Estado, dizia que a maioria daqueles miseráveis habitantes do sertão haviam sido condenados à cadeia, ao degredo ou à forca e, ao enfatizar que somente as vilas de São Salvador de Campos, São João da Barra, Paraty, Angra dos Reis, Santo Antônio de

21 Dentro dos limites da cidade do Rio de Janeiro surgiram as de São José, Santa Rita, Engenho Velho e Paquetá, às quais devem ser somadas as existentes em Cabo Frio e Campos dos Goitacazes, capitanias anexadas à do Rio de Janeiro antes de $\mathbf{1 7 5 9}$.

22 Arquivo da Cúria Metropolitana do Rio de Janeiro, códice VR 1.

23 Em 1749, com a efetivação dos corpos auxiliares, acompanhados das milícias e terços - agrupamentos armados existentes desde os primeiros séculos da colonização - a segurança da costa e do interior parecia estar assegurada. No entanto, uma Carta Régia de março de 1766 determinou o recrutamento dos moradores de todas as comarcas para a reorganização dos terços, tropas auxiliares, ordenanças e dos regimentos de Cavalaria e Infantaria. No ano seguinte, com a vinda do general Bohm como inspetor geral das forças, o vice-rei escreveu ao secretário de Estado da Marinha e Ultramar relatando os problemas para o recrutamento e sugerindo, além do aumento dos soldos e do controle do número de padres na capitania, o estabelecimento de povoados, vilas e baluartes fortificados nos pontos estratégicos do litoral fluminense, utilizando-se os rendimentos da Casa da Moeda do Rio de Janeiro (Projeto Resgate AHU_ACL_CU_017, Cx. 77, D. 6.968; AHU_ACL_CU_017, Cx. 80, D. 7.213; AHU_ACL_CU_ol, $\bar{C} x . \overline{8}$ o, D. 7.219; AHU_ACL_CU_ol7, $\bar{C} x . \overline{1}, \mathrm{D}$. $7 \cdot 277)$. 
Sá de Macacu e a cidade de Cabo Frio poderiam recebê-los, sugeriu a fundação de freguesias junto à baía do Rio de Janeiro ${ }^{24}$.

Os atos preconizados pelo marquês de Pombal, com suas posições anticlericais, proibindo os noviciados, as heranças e doações, monitorando o patrimônio religioso e alienando parte de seus bens, ocasionaram a repreensão ao bispo do Rio de Janeiro que teria efetuado mais de sessenta ordenações de padres dos cleros regular e secular para atender às inúmeras paróquias "dispersas pelo vasto território"25. A autoridade sobre a igreja incluía a apresentação de dados acerca da distribuição e gestão das comarcas, paróquias e vigararias com a descrição detalhada do número de ermidas dependentes, o valor das côngruas e de outros rendimentos dos párocos, cônegos, beneficiados e capelães. Tal repertório, elaborado antes de 1777 quando da saída do primeiro ministro, foi uma das fontes do trabalho realizado por monsenhor Pizarro, iniciado em 1781. Suas anotações originais, referentes àquelas localizadas no recôncavo norte ocidental, enseada de Angra dos Reis e da vila de Santo Antônio de Sá, divulgadas em 1794, tornaram-se elementos fundamentais para a elaboração do quadro 1.

Variadas informações podem ser verificadas. Em primeiro lugar, afora a importância das datas das capelas para o acompanhamento da colonização em terras fluminenses, chama atenção o fato de todas já serem coladas em 1755 com exceção das antigas reduções indígenas. Isto significa dizer que, apesar da política laicizante, mesmo no período pombalino estaria preservada a mistura do negócio público e eclesiástico com as matrizes, assumindo funções administrativas, militares e fiscais e, por esta razão, sustentadas pela metrópole. Uma informação adicional: ainda que a formação teológica dos clérigos fosse limitada, era bastante elevada em relação à população em geral, justificando-se, assim, sua remuneração anual. Pizarro indica, em seu texto, que o bispo recebia 500\$000 réis, a côngrua para o pároco de uma capela colada era de $200 \$ 000$ réis e de $25 \$$ réis ao coadjutor (ajudante ou substituto de um prior ou prelado). A ajuda real ao quizamento para as igrejas variava de $23 \$ 900$ a $25 \$ 000$ réis $^{26}$.

24. Projeto Resgate AHU_ACL_CU_o17, Cx. 80, D. 7.174; AHU_ACL_CU_o17, Cx. 80, D. 7.218.

25 Projeto Resgate AHU_ACL_CU_o17, Cx. 79, D. 7.133.

26 A título de comparação, um capelão de engenho recebia 5o\$ooo réis, o mestre do açúcar 100\$000, o padre com missão entre os índios $200 \$ 000$ e o capelão da aldeia $100 \$ 000$. 
As atividades agrícolas também merecem comentários e contribuem aqui para a compreensão de seu elo com os núcleos urbanos ${ }^{27}$. Verifica-se a correlação entre o número de vizinhos ${ }^{28}$, de engenhos e/ou de engenhocas e a criação das prelazias - Campo Grande, Pilar do Iguaçu, Inhomirim, Magé, Itaboraí e Icaraí - ou das vilas - Angra (1608), Paraty (1654), Santo Antônio de Sá (1697), Itaboraí (1773) e Magé (1789). A “nobreza da terra" doava terrenos para a edificação e o patrimônio das paróquias e ocupava cargos públicos, inclusive militares, reforçando, com seu prestígio, as relações pessoais de dependência, de fidelidade e de sociabilidade nas aglomerações. Na documentação pesquisada, observouse também a propriedade de engenhos das ordens beneditina (Jacarepaguá e Ilha do Governador) e carmelita (Guaratiba, Angra, Magé e Santo Antônio de Sá) em localidades servidas por rios ou de frente para o mar. Quanto aos ancoradouros, desempenharam importante função os portos de Santo Antônio do Mato (Jacutinga), de Estrela (Inhomirim), dos rios Macacu, Mauá (Pacobaíba), Suruí e de Iguassu - os dois que recebiam barcos maiores e o porto das Caixas (Itaboraí) com seu empório. No de Magé, onde havia um abundante comércio, o valor dos sobrados negociados era o mais alto da capitania, e o de São Gonçalo apresentava os preços de engenhos, fazendas e de sítios acima da média do Rio de Janeiro ${ }^{29}$. Ainda relativo ao transporte da produção agrícola e ao acesso a Minas foram fundamentais para a "interiorização da metrópole" os caminhos Novo (com o registro e a passagem de barcas pelo rio Paraíba em Nossa Senhora da Conceição), do Tinguá, da Serra do Couto e de Inhomirim. Pode-se ainda atentar para a relação entre o número total da população, de fogos, de engenhos e de engenhocas e a produção de alimentos. No último quartel do século XVIII, Santíssima Trindade, Itaboraí, Jacutinga,

27 BLOCH, March. La terre et le paysan: agriculture et vie rurale aux $17 \mathrm{e}$ et $18 \mathrm{e}$ siècles. Paris: Armand Colin, 1999 .

28 "É muito certo que o total de Almas compreende mais de uma terceira parte porque ordinariamente os brancos e pardos solteiros e libertos, que tem ser apreendidos para soldados, jamais se manifestam; antes procuram ocultar-se quanto podem. Os senhores de escravos igualmente ocultam ao Rol todos os que tem, subtraindo muitas vezes uma boa parte deles, e alguns até a metade desde que os Dizimeiros excogitaram o meio de obterem Portarias de V. Excia., para tirarem dos Róes das Freguesias o número dos escravos e fazerem os seus ladroados ajustes [...]. Em conseqüência deste procedimento padecem os Párocos com as faltas de satisfação aos seus reditos" (ACMRJ, Livro de visitas, fl. 81).

29 Segundo as 200 escrituras públicas de compra e venda de propriedades (período $175^{\circ} / 1790$ ) que apresentam o valor das transações de um total de 262 registros levantados no Arquivo Nacional. PESAVENTO, Fábio. Um pouco antes da corte: a economia do Rio de Janeiro na segunda metade do Setecentos. Faculdade de Economia/UFF, 20o9. (Tese de doutoramento). Trata-se de uma amostragem, pois a maioria dos negócios se fazia sem a oficialização nos cartórios. 
Iguassu, Angra dos Reis e Paraty tornaram-se importantes produtoras de farinha; a freguesia de Inhomirim foi responsável pela metade da colheita de milho da capitania, seguida por Itaboraí, onde a lavra do feijão também se distinguia, além do cultivo de arroz nas terras de Jacutinga e Iguassu. E Paraty ainda se tornou famosa por seus alambiques de aguardente.

Constata-se também a presença de ricas famílias em diferentes localidades - Corrêa (Campo Grande e Meriti); Costa Barros (Magé e São Gonçalo); Gago (Irajá e Guapimirim); Maxado (Irajá, Inhomirim e Rio Bonito); Oliveira Braga (Irajá, Guaratiba, Jacutinga e Santíssima Trindade); Pereira da Silva (São Gonçalo e Santíssima Trindade); Moreira de Soiza (Pilar e Piedade do Iguassu); Soiza (Angra, Irajá e Meriti); Suzano (Campo Grande e Angra) e os parentes Pereira Ramos, Azevedo Ramos, Andrade Sotto Maior e Werneck (Marapicu, Jacutinga, Alferes e São Gonçalo). E de clãs com forte influência em uma freguesia - Antunes de Andrade (Santo Antônio de Sá); Azeredo Coitinho (Itaboraí); Bustamante (São Gonçalo); Gonçalves Portugal (São João Marcos); Paes Leme (caminho do Tinguá); Ribeiro de Avelar (Alferes); Teles Barreto de Menezes (Jacarepaguá) e Vasques (Jacutinga). Além do tráfico de escravos, da importação de panos ou empenhados nas atividades de crédito e de seguros, alguns "homens de grossa aventura" e membros da nova elite econômica ${ }^{30}$ também eram senhores de engenho - é o caso de Braz Carneiro Leão (Santo Antônio de Sá e Itambi) e os Velho (Inhomirim, São Gonçalo e Itambi).

Excluindo os antigos aldeamentos e as freguesias erigidas nos caminhos que levavam às minas, monsenhor Pizarro apresenta ainda em seus relatos a presença de confrarias que representavam classes de renda, cor ou ofícios. Estavam presentes as irmandades do Santíssimo Sacramento congregando os brancos mais aquinhoados e de destaque da elite $^{31}$; de Nossa Senhora do Rosário, São Benedito, Santa Efigênia e de Nossa Senhora dos Remédios Padroeira, organizadas pelos negros cati$\operatorname{vos}^{32}$, e aquelas que representavam os pardos, cativos ou libertos - Nossa Senhora da Conceição e da Boa Morte, Nossa Senhora da Conceição dos Homens Pardos, Nossa Senhora do Amparo, Nossa Senhora da Lapa,

30 FRAGOSO, João. A noção de economia colonial tardia no Rio de Janeiro e as conexões econômicas do Império português 1790-1820. In: . ; BICALHO, Maria Fernanda; GOUVÊA, Maria de Fátima (Orgs.). O antigo regime nos trópicos. Rio de Janeiro: Civilização Brasileira, 2001.

31 Exceto nas paróquias de Nossa Senhora da Ajuda de Guapimirim e da Santíssima Trindade.

$3^{2}$ Salvo Nossa Senhora do Desterro de Campo Grande e Nossa Senhora da Ajuda da Ilha do Governador. 
Nossa Senhora do Socorro dos Homens Pardos, São Gonçalo Garcia, São Braz, Bom Fim dos Pardos e Nossa Senhora do Terço. Quanto aos ofícios, afiançando a existência de atividades de caráter urbano, na irmandade de São Miguel e Almas reuniam-se os brancos e mestiços mais humildes que atuavam como boticários ${ }^{35}$, caixeiros (balconistas ou ambulantes), confeiteiros, tecelões, artesãos de adornos com azeviche, de pentes e de cordões de seda, funileiros e ferreiros. Em Pacobaíba, a Confraria de Nossa Senhora da Guia agrupava os artífices de artigos de couro e de fios, incluindo os de ouro; nas capelas de Santo Antônio de Sá e Guapimirim, os ceramistas, pedreiros, carpinteiros, ladrilhadores, marceneiros e mestres de obra formavam a Irmandade de São José e, em Paraty, os garimpeiros cultuavam o Senhor Bom Jesus dos Passos. Nos portos de Suruí e de Guapimirim, os marinheiros e soldados eram protegidos por São Nicolau e Nossa Senhora da Ajuda. Nossa Senhora da Piedade, adorada pelos viajantes e aventureiros em busca do ouro, tornou-se a padroeira das freguesias de Iguassu, Inhomirim e Magé, demonstrando que estas paragens eram pousos daqueles que seguiam para as minas pelo Caminho Novo ${ }^{34}$. Havia ainda os santos protetores da pecuária e da agricultura, como em Paraty aquela dedicada a São Roque, defensor do gado, e a consagrada a São Gonçalo, o patrono da fertilidade. E para os que deixaram sua terra, a devoção a Nossa Senhora do Desterro em Campo Grande e em Itambi.

Para concluir: na instalação de espacialidades urbanas, os dados relativos ao recôncavo norte ocidental, enseada de Angra dos Reis, e à vila de Santo Antônio de Sá revelam a relação simbiótica entre a metrópole e a Igreja em parceria com os donos de terras e de escravos. Se inicialmente partiam do litoral, aos poucos vastas áreas do interior foram atingidas e incorporadas sob suas jurisdições. Tais freguesias ou polos de "cristianização" permitem questionar a ideia consagrada segundo a qual uma base urbana fraca não propiciaria o surgimento de uma rede de cidades e considerar a existência de estratégias ou mesmo de um planejamento territorial no projeto ultramarino português.

33 Donos de botica, entendida aqui como farmácia, loja ou taberna.

34. Uma variante foi aberta a partir de Inhomirim, tornando-se sede de um distrito miliciano compreendendo Magé, Pacobaíba e Suruí. 


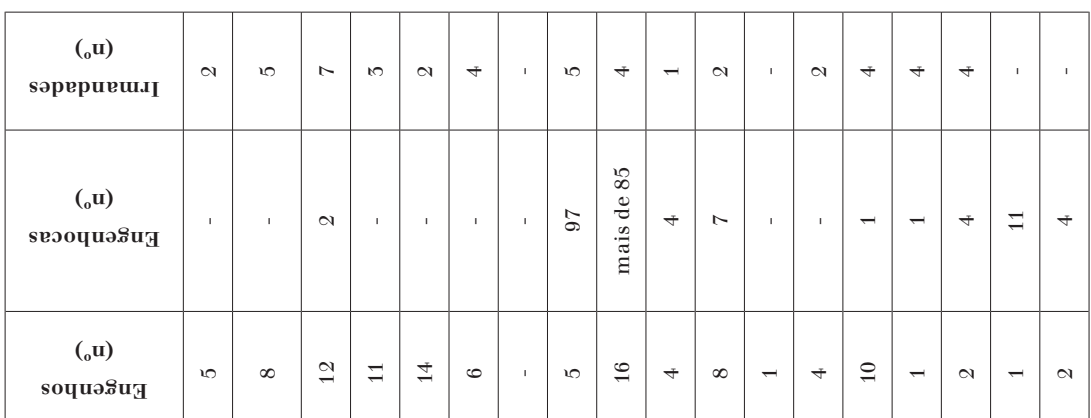

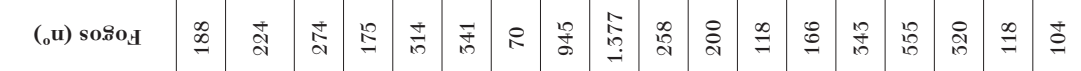

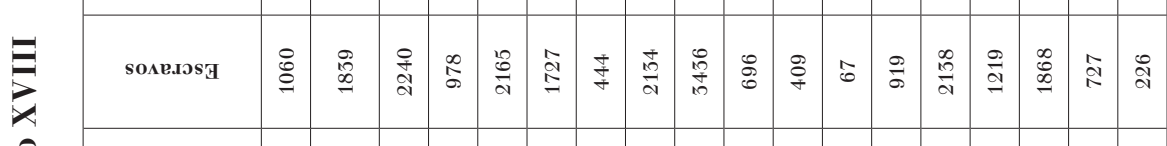

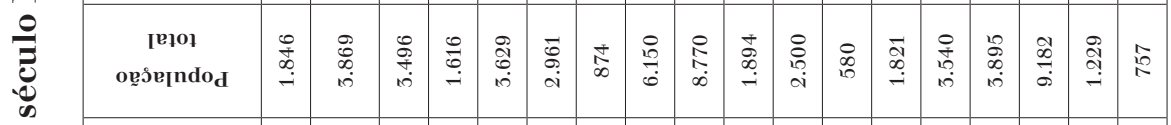

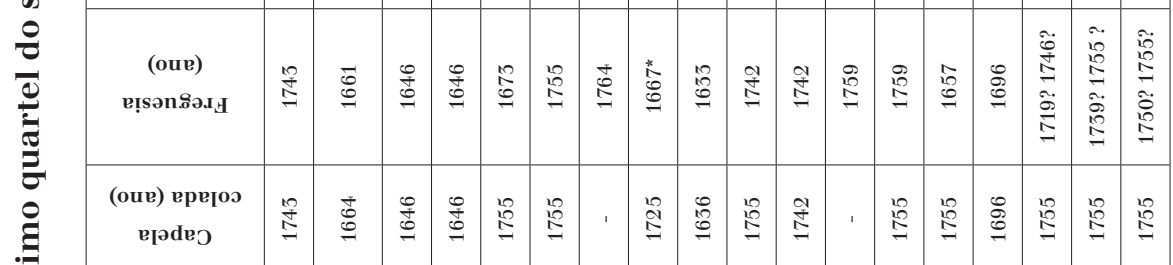

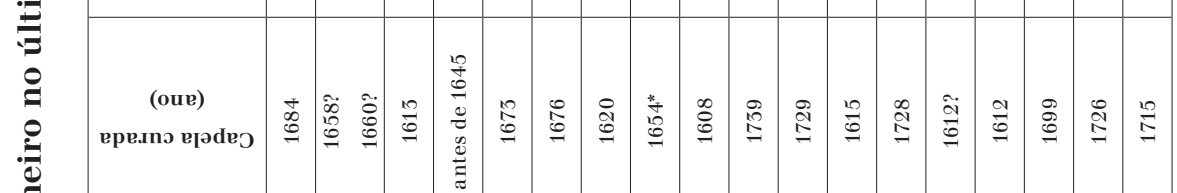

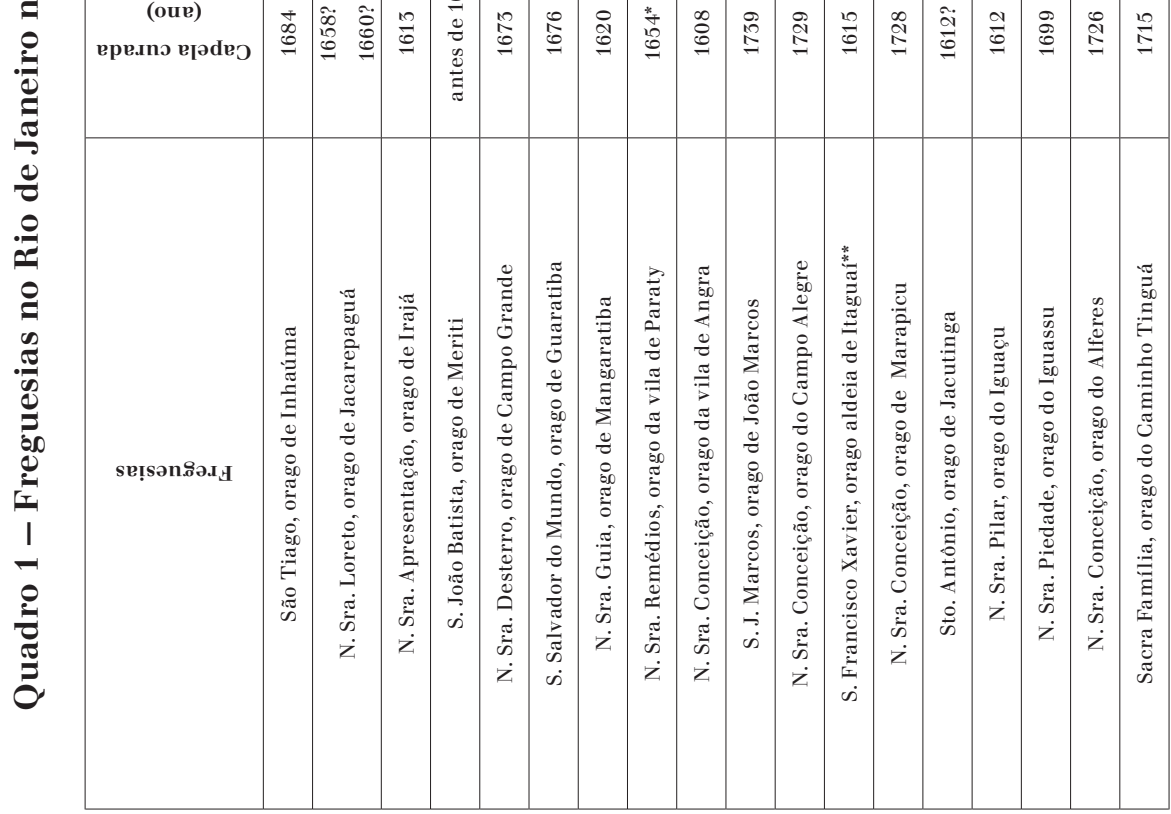




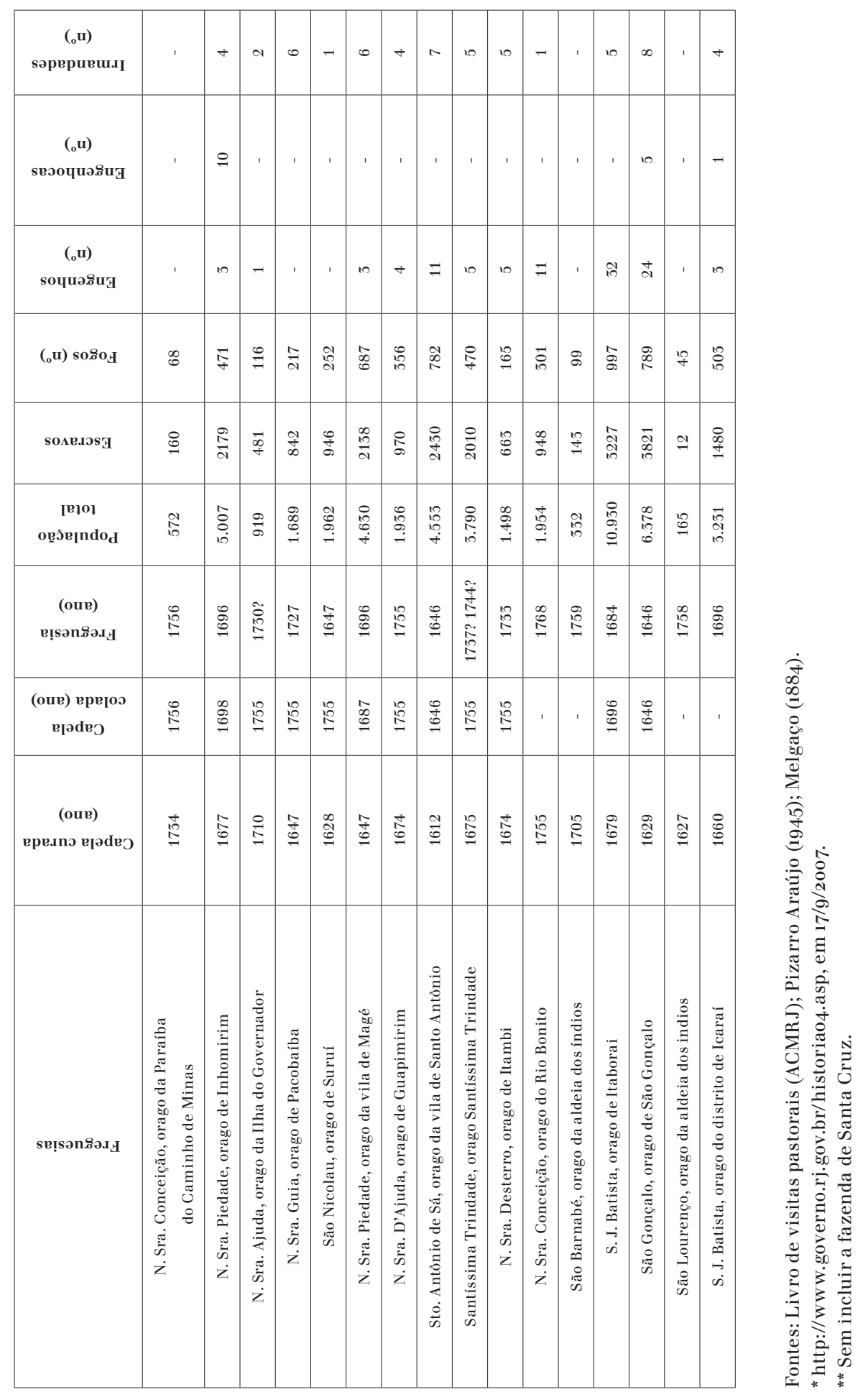




\section{Imagens do Artigo: Freguesias fluminenses ao final do Setecentos}

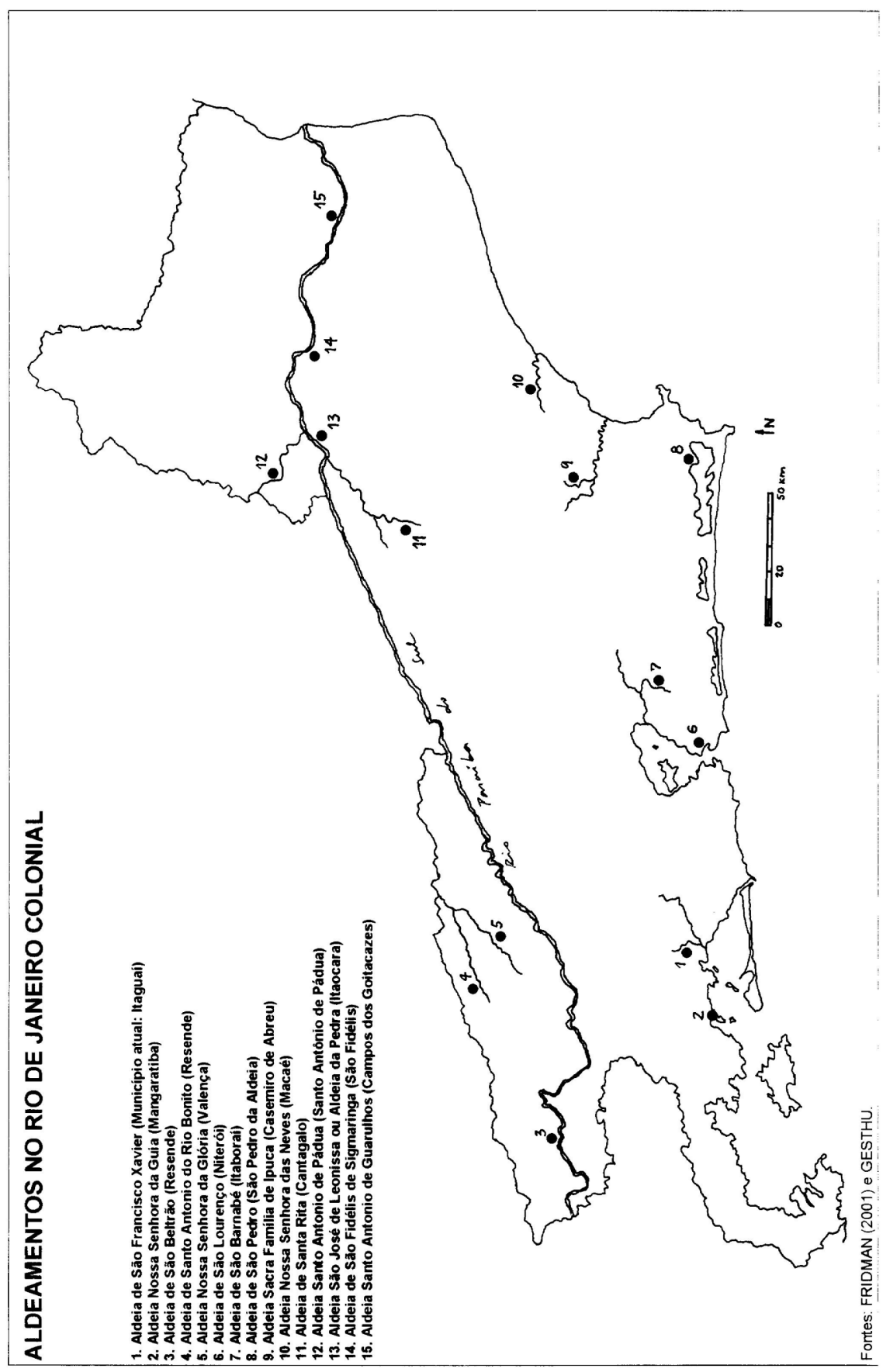




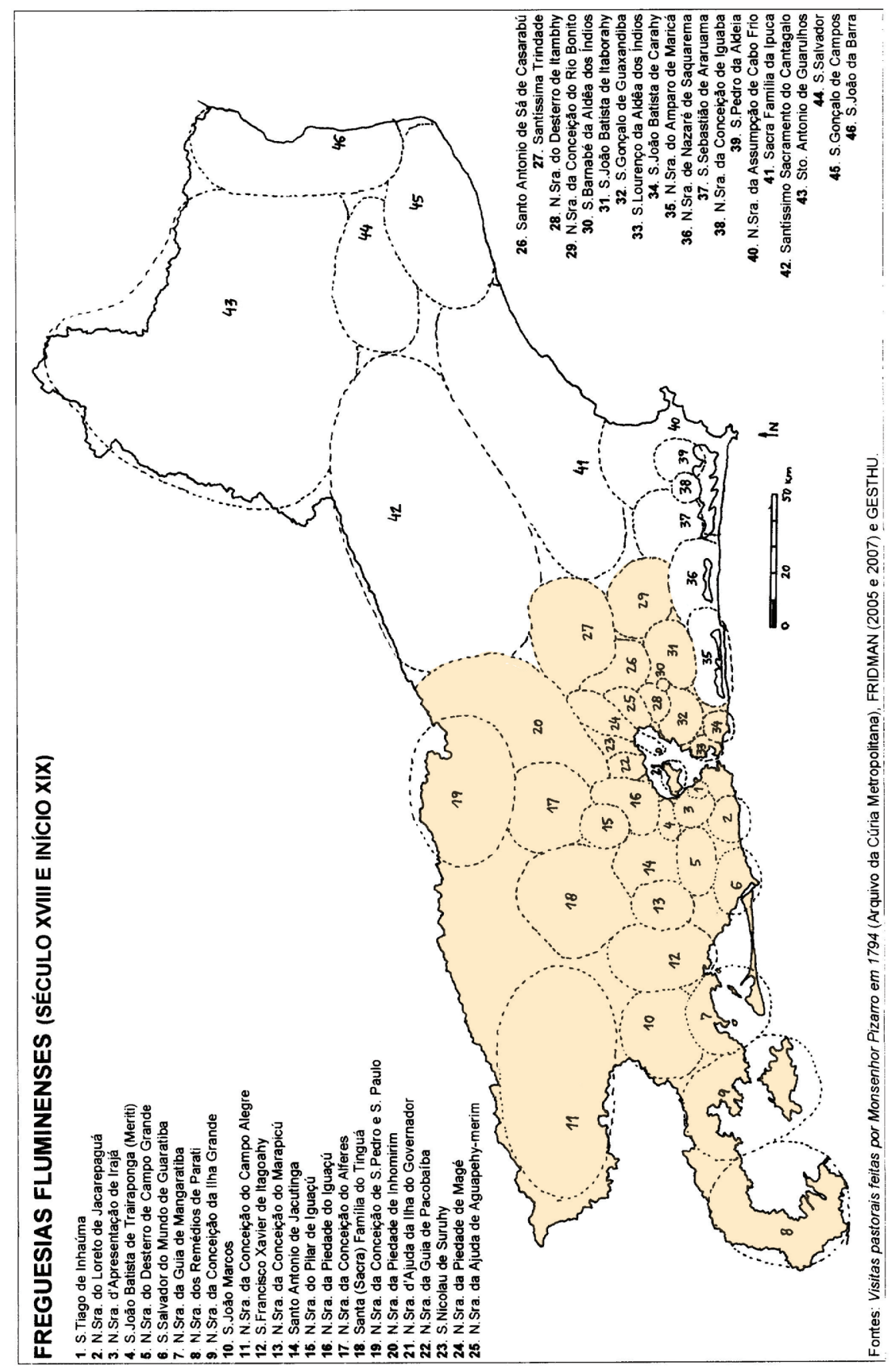

